\title{
Alternative Method to Evaluate Performance Improvement Rate in Athletics Middle Distance Events
}

\author{
Lucas Pinheiro Barbosa ${ }^{1} \cdot$ Patrick Aguiar Santos ${ }^{1} \cdot$ Samuel Silva Aguiar ${ }^{1} \cdot$ Herbert Gustavo Simões $^{1}$. \\ Pantelis Theodoros Nikolaidis ${ }^{2,3} \cdot$ Beat Knechtle $^{4,5}$ (Caio Victor Sousa ${ }^{6}$
}

Received: 25 December 2020 / Accepted: 7 July 2021 / Published online: 27 September 2021

(c) The Author(s) 2021

\begin{abstract}
Purpose The aims of this study were to propose an alternative method to assess an optimal performance improvement rate (PIR) that would be used as a tool for coaches and elite athletes willing to reach their personal best, mainly those seeking for national, continental or even world record (WR) in middle-distance events. We further compared the improvement rate of women vs. men of the top-10 ranked athletes in the IAAF running these middle-distance events

Method The top 10 athletes in the IAAF ranking of $800 \mathrm{~m}, 1500 \mathrm{~m}$, and $3000 \mathrm{~m}$ events for each sex were assessed for their history of race times before achieving their personal record (PR). The difference between PR ('actual' season) and the best race time in the last season was defined as the 1st season improvement rate (1-SIR), whereas the average improvement rate in the last and preceding seasons was the multi-season improvement rate (M-SIR). 1-SIR and M-SIR were calculated for each athlete.

Result There were sex differences in the $1500 \mathrm{~m}$ with a large effect size $(d=-0.746)$ in 1-SIR $(P=0.001)$ and very large $(d=-2.249)$ in M-SIR $(P=0.001)$. Women improved more than men before the PR/WR achievements in the $800 \mathrm{~m}$ and $1500 \mathrm{~m}$ events $(P=0.001)$ and had similar improvement rates before performing PR/WR in $3000 \mathrm{~m}$ events $(P=0.533)$.

Conclusion Women improve more before PR/WR achievement in $800 \mathrm{~m}$ and $1500 \mathrm{~m}$ races. However, in the $3000 \mathrm{~m}$ men and women have similar improvement rates in previous seasons before the PR/WR achievement.
\end{abstract}

Keywords Performance $\cdot$ Running $\cdot$ Track-and-field $\cdot$ Middle-distance $\cdot$ Athletics

\section{Introduction}

Beat Knechtle

beat.knechtle@hispeed.ch

1 Graduate Program in Physical Education, Catholic University of Brasília, Brasília, DF, Brazil

2 Exercise Physiology Laboratory, Nikaia, Greece

3 School of Health and Care Sciences, University of West Attica, Athens, Greece

4 Medbase St. Gallen Am Vadianplatz, Vadianstrasse 26, 9001 St. Gallen, Switzerland

5 Institute of Primary Care, University of Zurich, Zurich, Switzerland

6 Bouve College of Health Sciences, Northeastern University, Boston, MA, USA
Athletics is one of the most classic and old sport worldwide, composed of a set of modalities involving the basic movements of the human species, such as walking, running, jumping, and throwing [35]. The modern athletics began in the 19th century with the first modern Olympic Games in 1896 in Athens, Greece, and since 1912 the International Athletics Amateur Federation (IAAF) became the entity responsible for taking care of the athletics all over the world [17].

Throughout more than a century of Olympic Games and World Championships humans are always breaking records and achieving a new level of human capacity [24, 31]. This fact has increased curiosity and research on the lifestyle and peak performance of athletes, increasing the development of different health maintenance and training strategies and other tools to achieve and predict athlete performance $[5,6,21]$. 
Some studies have sought to investigate the progression of human performance over decades, comparing men to women and age-related peak performance $[5,8$, 27]. For example, Berthelot et al. [5], when analyzing the $400 \mathrm{~m}$ running and $100 \mathrm{~m}$ freestyle swim performance in the Olympics (1890-2010), identified that athletes of both sexes improved their performance throughout decades, and suggested that both physiological and technological aspects as the main reasons for the performance improvement. Coast et al. [8] compared the performance of the best men and women registered in the IAAF and the American Association of Ultradistance in tests of $100 \mathrm{~m}-200 \mathrm{~km}$. The results did not identify a tendency to decrease the difference between the sexes, in addition, in longer races, men seemed to perform significantly better.

In the case of middle-distance running, which comprehends distances from $800 \mathrm{~m}$ up to $3000 \mathrm{~m}$ dash [14] and presents a high metabolic demand, mixing power from aerobic and anaerobic sources [6], little is known. In addition, it is worth mentioning that, from $800 \mathrm{~m}$, the predominance of aerobic metabolism for energy supply begins. For instance, in $800 \mathrm{~m}$ events, athletes have a contribution of aerobic energy sources of about $60 \%-70 \%[13,29]$ whereas, in the events of $1500 \mathrm{~m}$ and $3000 \mathrm{~m}$ the aerobic energy contribution is around $75 \%-90 \%$. However, since these races $(800 \mathrm{~m}, 1500 \mathrm{~m}$ and $3000 \mathrm{~m}$ ) are performed above the anaerobic threshold (AT), the contribution of anaerobic energy sources is essential to maintain the desired velocity [14], pointing out that such races may have similar performance determinants.

Coaches and athletes wishing to win an athletics running race and/or to break specific records (i.e. area, continental or even a world record) could base their training goals by simply: "achieving a faster race time than the actual winner". However, this shallow perception could preclude coaches and athletes to achieve long-term results and the detection of young talents. Besides, methods of physical/physiological, health assessments and monitoring of athletes have been used by the technical committees in several sports, such as soccer [7, 9, 22], football $[23,28,32]$ and athletics [20, 30]. Recently, Santos et al. [26] designed a new method to evaluate the rate of performance improvement in speed tests $(100 \mathrm{~m}$ and $400 \mathrm{~m})$, in addition, they concluded that to obtain the record in the $100 \mathrm{~m}$, women need to evolve 0.093-0.491 s annually, and for men, $0.068-0.226 \mathrm{~s}$. In turn, in the $400 \mathrm{~m}$ events, an evolution of $0.243-2.205 \mathrm{~s}$ per year was indicated for women, and for men between $0.253 \mathrm{~s}$ and $1.845 \mathrm{~s}$. However, there are still no methods in the literature for evaluating mid-distance events $(800 \mathrm{~m}, 1500 \mathrm{~m}$, and $3000 \mathrm{~m})$, which would assist coaches with a vast tool for the evolution of their sprinting and half-distance athletes.
Thus, the main objective of the study was to create an alternative method to assess an optimal performance improvement rate for coaches and athletes willing to achieve personal bests and perhaps reaching records in $800 \mathrm{~m}$, $1500 \mathrm{~m}$, and $3000 \mathrm{~m}$. We further compared the improvement rate of women vs. men of the top-10 ranked athletes in the IAAF running these middle-distance events.

\section{Methods}

All procedures used in the study were approved by the Institutional Review Board of Kanton St. Gallen, Switzerland, with a waiver of the requirement for informed consent of the participants given the fact that the study involved the analysis of publicly available data. Data were extracted from the publicly available database of the IAAF (www.iaaf.org). The first ten female and male athletes in the World Record rank of $800 \mathrm{~m}, 1500 \mathrm{~m}$, and $3000 \mathrm{~m}$ events composed this sample. The athletes had recorded their date of birth, nationality, best race time of their career (the one that got the athlete in their World Ranking position; personal record; PR), the best race time in the season immediate before the PR, and the best race time in two or more seasons before the PR.

The difference between the PR and the best race time in the season immediately before is the 1-season improvement rate (1-SIR), whereas the average improvement rate in the season immediate before and two to five seasons before that is the multi-season Improvement Rate (M-SIR). These variables (1-SIR and M-SIR) were calculated individually. Further calculations in relative (\%) measures were also included. Descriptive analysis of all data was performed and is displayed in Table 1. All data were tested for normality and homogeneity using Shapiro-Wilk's and Levene's tests, respectively. Variables were compared between females and males using a Student's $t$ test for independent samples. Cohen's $d$ was used to calculate effect sizes [10].

Furthermore, using the descriptive data (mean, standard deviation, and range), we generated a list of one thousand random entries to compose a Strauss curve for the index in each group ( $800 \mathrm{~m}, 1500 \mathrm{~m}$ and $3000 \mathrm{~m}$; females and males). Although the generated numbers are random, the variance and central tendencies are real, which will fulfill the purpose of this manuscript. All procedures considered an $\alpha<0.05$. All statistical procedures were performed using Statistical Software for the Social Sciences (SPSS v.21) and Microsoft Office Excel (MS Office 2016).

\section{Results}

No differences 1-SIR and M-SIR were identified between men and women $(P>0.05)$. The comparison between sexes for the $800 \mathrm{~m}$ event showed no significant difference 
Table 1 Descriptive data of 10 best all-time records in middledistance running in athletics

\begin{tabular}{|c|c|c|c|c|}
\hline & \multicolumn{2}{|l|}{ Male } & \multicolumn{2}{|l|}{ Female } \\
\hline & Mean (SD) & Range (min-max) & Mean (SD) & Range (min-max) \\
\hline \multicolumn{5}{|l|}{ Age $(y)$} \\
\hline $800 \mathrm{~m}$ & $22(2)$ & $18-25$ & $26(3)$ & $19-32$ \\
\hline $1500 \mathrm{~m}$ & $25(2)$ & $22-28$ & $22(4)$ & $18-29$ \\
\hline $3000 \mathrm{~m}$ & $24(3)$ & $20-30$ & $30(20)$ & $20-86$ \\
\hline \multicolumn{5}{|c|}{ Race time (s) } \\
\hline $800 \mathrm{~m}$ & $101.85(0.51)$ & $100.91-102.37$ & $114.46(0.70)$ & $113.28-115.19$ \\
\hline $1500 \mathrm{~m}$ & $207.69(1.06)$ & $206.00-208.80$ & $232.33(1.60)$ & $230.07-234.23$ \\
\hline $3000 \mathrm{~m}$ & $445.34(2.13)$ & $440.67-447.55$ & $498.35(5.31)$ & $486.11-502.20$ \\
\hline \multicolumn{5}{|l|}{ 1-SIR (s) } \\
\hline $800 \mathrm{~m}$ & $1.71(1.67)$ & $0.16-5.55$ & $3.18(2.48)$ & $0.24-6.57$ \\
\hline $1500 \mathrm{~m}$ & $1.90(0.91)^{*}$ & $0.61-3.24$ & $7.85(3.61)$ & $2.85-11.78$ \\
\hline $3000 \mathrm{~m}$ & $6.97(5.53)$ & $0.93-17.42$ & $11.44(10.03)$ & $2.77-30.36$ \\
\hline \multicolumn{5}{|l|}{ 1-SIR (\%) } \\
\hline $800 \mathrm{~m}$ & 1.67 & $0.15-5.42$ & 2.77 & $0.21-5.70$ \\
\hline $1500 \mathrm{~m}$ & 0.91 & $0.29-1.55$ & 3.37 & $1.23-5.02$ \\
\hline $3000 \mathrm{~m}$ & 1.56 & $0.21-3.89$ & 2.29 & $0.56-6.04$ \\
\hline \multicolumn{5}{|l|}{ M-SIR (s) } \\
\hline $800 \mathrm{~m}$ & $2.05(1.86)$ & $0.10-5.18$ & $3.04(2.04)$ & $1.03-5.77$ \\
\hline $1500 \mathrm{~m}$ & $3.02(2.00)^{*}$ & $0.87-7.55$ & $13.75(7.64)$ & $7.27-23.21$ \\
\hline $3000 \mathrm{~m}$ & $10.41(5.47)$ & $3.93-21.24$ & $11.31(6.43)$ & $4.93-17.37$ \\
\hline \multicolumn{5}{|c|}{ M-SIR (\%) } \\
\hline $800 \mathrm{~m}$ & 2.01 & $0.09-5.06$ & 2.65 & $1.02-5.00$ \\
\hline $1500 \mathrm{~m}$ & 1.45 & $0.42-3.61$ & 5.91 & $3.15-9.90$ \\
\hline $3000 \mathrm{~m}$ & 2.33 & $0.89-4.76$ & 2.26 & $1.01-3.45$ \\
\hline
\end{tabular}

1-SIR 1 -season improvement rate, $M$-SIR multi-season improvement rate average

*Differences between sex at $P<0.05$
$(P>0.05)$, however, in the M-SIR, there was a moderate effect size $(d=-0.544)$ (Fig. 1B). However, with regard to $1500 \mathrm{~m}$, women presented higher 1-SIR $(P=0.001)$ and M-SIR $(P=0.001)$ than men, with stratified effect size in large $(d=-0.746)$ and very large $(d=-2.249)$, respectively (Fig. 1C and D). In contrast, there were no significant differences $(P>0.05)$ in $3000 \mathrm{~m}$ as well as a trivial effect in 1-SIR and M-SIR $(d=-0.440$ and -0.321 , respectively).

The method for optimal performance improvement rate assessment was generated from the actual data of the best athletes of each category (female, male) in the events of $800 \mathrm{~m}, 1500 \mathrm{~m}$, and $3000 \mathrm{~m}$ and are shown in Fig. 2. The mean is the central value of each curve and the distance (number of deviations standard) indicates whether a certain athlete is improving more or less than the best athletes of the event. A practical approach to these results is provided in more detail in the chapter on practical applications.

\section{Discussion}

The main objective of the study was to create an improvement rate index for coaches and athletes intending to achieve records in $800 \mathrm{~m}, 1500 \mathrm{~m}$, and $3000 \mathrm{~m}$ and to compare the rate of improvement between women and men of the best athletes in these events. When analyzing the $800 \mathrm{~m}$ and $3000 \mathrm{~m}$ events, no statistical difference was found between the sexes. However, in the $1500 \mathrm{~m}$ event, women improve more than men in the seasons before achieving PR/WR.

The middle-distance running races have a fundamental anaerobic contribution, but the main contribution is from the aerobic energy system, which possibly explains why men have a greater advantage in relation to women since they have more muscle mass, greater anaerobic capacity, and consequently, more strength and power [8, 27]. However, Seiler et al. [27] compared the time of power tests between men and women, dividing them from 1980 to 1988 and 2000-2005, and found that the differences rose from $9.8 \%$ 

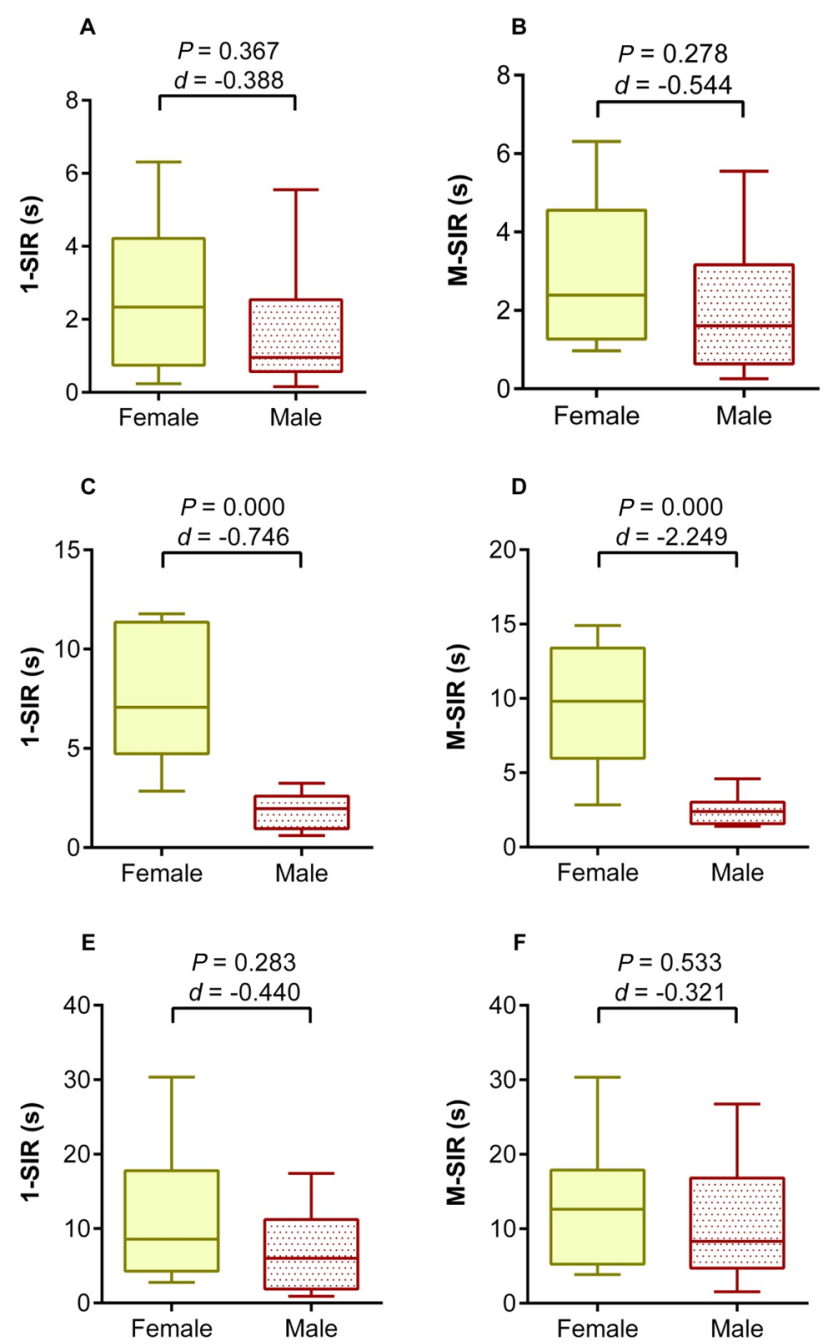

Fig. 1 Boxplots and effect size of 1-SIR and M-SIR the female and male $800 \mathrm{~m}, 1500 \mathrm{~m}$ and $3000 \mathrm{~m}$

to $11.2 \%$ in the mentioned years cited above, showing that even though women are improving, the gender gap is still significant. In order to minimize the gap between the sexes, most coaches have sought to group their athletes to reduce technical differences, as well as to motivate the slower to approach the faster ones [27].

With regard to the measure of performance improvement proposed here, perhaps, to know the annual performance gain of these athletes may help the interventions of the coaches of these modalities $[2,11,16]$. It is also known that there are cut-off indices to enter the professional sport and to qualify for World Championships and Olympic Games. Therefore, annual monitoring of the athlete is necessary to keep them at a competitive level.

This study is aligned with current World Records in $800 \mathrm{~m}, 1500 \mathrm{~m}$, and $3000 \mathrm{~m}$, from which the improvement rates (\%) season by season are similar to the present results. We showed that the average improvement of men from the previous season to the breaking record season was $1.71 \mathrm{~s}$ (1.67\%), $1.90 \mathrm{~s}(0.91 \%)$, and $6.97 \mathrm{~s}(1.56 \%)$ for the $800 \mathrm{~m}$, $1500 \mathrm{~m}$, and $3000 \mathrm{~m}$, respectively. With the exception of D.R., who holds the world record of $800 \mathrm{~m}$, improved only $0.41 \%$ (below the estimated average) of the previous season by breaking the record, holders of the $1500 \mathrm{~m}$ (HG) and $3000 \mathrm{~m}$ (DK), showed an improvement over the previous season of $2.91 \mathrm{~s}(1.39 \%)$ and $17.42 \mathrm{~s}(3.95 \%)$, respectively [17], which is above the estimated average. Thus, as expected, races with longer distances and, in turn, more time-consuming, offer possibilities of improvement of greater magnitude, as determined by the law of initial values [33].

However, the athletes may not achieve an improvement in performance every year, and some researchers have come up to study some determining factors for performance increase and success in World Championships and Olympic Games. Ingham et al. [18] reported that $95.9 \%$ of the best performance in $800 \mathrm{~m}$ and $1500 \mathrm{~m}$ comes from the perfect relationship between $\mathrm{VO}_{2 \max }$ and running economy (RE). The authors suggested that for an excellent performance, an excellent running technique/mechanics performed at high velocity is necessary. Deason et al. [12] revealed that the velocity of $\mathrm{VO}_{2 \max }\left(\mathrm{vVO}_{2 \max }\right)$, the percentage of body fat, and RE correlate to $89 \%$ of final performance of $800 \mathrm{~m}$ in both men and women. These results cooperate for coaches to find out where the potential mismatch might be hampering their athletes' progress to the world record.

Yoshida et al. [34] investigated the variables that may be more associated with performance in the $800 \mathrm{~m}, 1500 \mathrm{~m}$, and $3000 \mathrm{~m}$ races, found that, for the $800 \mathrm{~m}$, the best associated variable with performance was the $\mathrm{VO}_{2 \max }$ at the lactate threshold $(r=0.77 ; P<0.01)$, and for the races of 1500 and $3000 \mathrm{~m}$ was the velocity at onset blood lactate accumulation (OBLA), being: $r=0.85(P<0.01), r=0.88(P<0.01)$, for the 1500 and $3000 \mathrm{~m}$, respectively. Thus, it is reasonable to infer that, as expected, the $800 \mathrm{~m}$ run seems to be more dependent on aerobic power $\left(\mathrm{VO}_{2 \max }\right)$, whereas races of 1500 and $3000 \mathrm{~m}$ may be more dependent on aerobic capacity (OBLA). Furthermore, studies have shown that muscle strength plays a key role in athletic performance [3, 4]. Bachero-Mena et al. [3] have shown a positive relationship between the increase in muscle strength, measured through the countermovement jump and full squat, and a significant performance enhancement $(\sim 3 \mathrm{~s})$ in $800 \mathrm{~m}$ in elite athletes.

On the other hand, Sandford et al. [25] showed that $\mathrm{vVO}_{2 \max }$ has a major contribution to performance in middle-distance events, noting that, although races of 1500 and $3000 \mathrm{~m}$ show a little more dependence on the aerobic capacity, that is, the velocity at anaerobic threshold, the aerobic power variable (velocity at $\mathrm{VO}_{2 \max }$ ) still seems to be the best predictor of performance in any of the medium distance races $(800 \mathrm{~m}, 1500 \mathrm{~m}$ and $3000 \mathrm{~m})$. Therefore, these two 

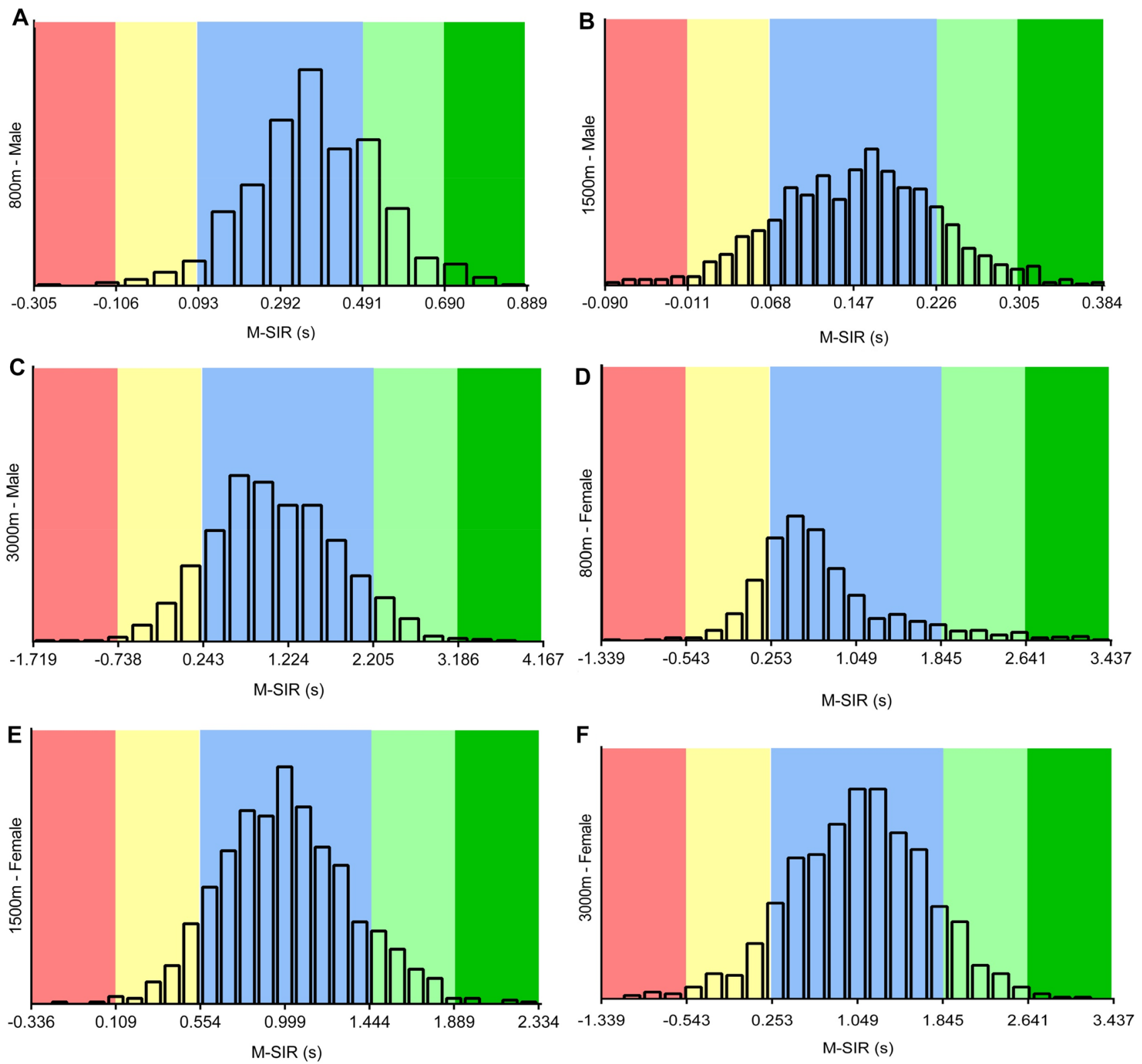

Fig. 2 Improvement rate index for the $800 \mathrm{~m}, 1500 \mathrm{~m}$ and $3000 \mathrm{~m}$ races for men and women

physiological variables (AT and $\mathrm{VO}_{2 \max }$ velocities) should be the aim for improvement in order to increase the chances of a PR that could lead to success in major sports events. In addition, for all athletics distances, biomechanical factors are also relevant and may directly influence the annual development of the athletes' performance. Low vertical oscillation, body posture along with the run are one of the most important components for performance $[1,15]$.

Moreover, Kyröläinen et al. [19] investigated electromyographic (EMG) activity at different velocities in runners of both sexes and found that with increasing speed the most recruited muscles are gluteus maximus, biceps femoris, and vastus lateralis. Therefore, in relation to strength training for these athletes, greater attention should be given to these muscle groups in order to aid in running mechanics at higher speeds. The present study seeks to assist practitioners working with elite male and female athletes of the $800 \mathrm{~m}, 1500 \mathrm{~m}$, and $3000 \mathrm{~m}$ races. Therefore, graphs have been produced to help to verify the improvement of the athletes, so that coaches can be assisted by it and know if the training sessions are producing the expected performance increase, or if some adjustments need to be made.

In conclusion, women improve more before the PR/WR achievement in $800 \mathrm{~m}$ and $1500 \mathrm{~m}$ races. However, in the $3000 \mathrm{~m}$ races men and women have similar improvement 
rates in previous seasons before the PR/WR achievement. Besides, the range of performance development for males was shown to be lower when compared to women in the $800 \mathrm{~m}$ and $1500 \mathrm{~m}$ races. In the $3000 \mathrm{~m}$ races, the optimal range of women's performance development is lower than that in men. The resulting graphs from personal improvement rate analysis may be useful for athletes and coaches to check the rate of improvement and verify whether a long-term training strategy has improved performance considerably to reach purposes (i.e. reaching personal best that perhaps would result in a record) or if some adjustments are needed on the training process.

Future research could focus on other modalities in athletics and the training and health strategies of world record athletes.

\section{Practical Applications}

To apply the results from the index, an athlete should consider his best race time from the present season minus his race time from immediate (or three seasons before). This number is his rate of improvement and could be compared to the best ten runners within his event. Considering the plots (Fig. 2), if the rate of improvement falls within:

Blue range $( \pm 1 \mathrm{SD})$ : improves within the average of top-10 runners; Yellow range $(-2 \mathrm{SD})$ : improves below the average of top-10, should consider a change of strategy in training; Red range ( $-3 \mathrm{SD}$ ): improves significantly below the average of top-10, should consider a major change of strategy in training; Green $(+2 \mathrm{SD})$ : improves above the average of top-10, training strategy is effective and it is worth investigating the possible causes; Dark green (+3 SD): improves significantly above the average of top-10, training strategy is very effective and should be investigated the possible causes; doping agencies should also consider an extra care.

Example: John races the $800 \mathrm{~m}$-dash with his best race time in two past seasons being $105 \mathrm{~s}$ and $106 \mathrm{~s}$. In the present season, John performed $104.5 \mathrm{~s}$.

\begin{tabular}{lll}
\hline Year & $\begin{array}{l}\text { Performance } \\
(\mathrm{s})\end{array}$ & Rate of improvement (s) \\
\hline 2005 & 106.4 & - \\
2006 & 106.0 & 0.4 \\
2007 (present) & 105.5 & 0.5 \\
Average rate of improvement & 0.45 \\
\hline
\end{tabular}

Considering the plot from Fig. 2-A for males within the $800 \mathrm{~m}$ and average rate of $0.45 \mathrm{~s}$, John falls within the blue range. Meaning that the strategy seems to be correct, and a projection considering his target race event (Nationals, World Championship, Olympics, etc.) could be planned.
Funding Open Access funding provided by Universität Zürich. Not applicable.

Availability of Data and Material Not applicable.

Code Availability Not applicable.

\section{Declarations}

Conflicts of interest The author reports no conflicts of interest in this work.

Open Access This article is licensed under a Creative Commons Attribution 4.0 International License, which permits use, sharing, adaptation, distribution and reproduction in any medium or format, as long as you give appropriate credit to the original author(s) and the source, provide a link to the Creative Commons licence, and indicate if changes were made. The images or other third party material in this article are included in the article's Creative Commons licence, unless indicated otherwise in a credit line to the material. If material is not included in the article's Creative Commons licence and your intended use is not permitted by statutory regulation or exceeds the permitted use, you will need to obtain permission directly from the copyright holder. To view a copy of this licence, visit http://creativecommons.org/licenses/by/4.0/.

\section{References}

1. Anderson T. Biomechanics and running economy. Sports Med. 1996;22(2):76-89.

2. Angehrn N, Rüst CA, Nikolaidis PT, Rosemann T, Knechtle B. Positive pacing in elite IRONMAN triathletes. Chin J Physiol. 2016;59(6):305-14.

3. Bachero-Mena B, Pareja-Blanco F, González-Badillo JJ. Enhanced strength and sprint levels, and changes in blood parameters during a complete athletics season in $800 \mathrm{~m}$ high-level athletes. Front Physiol. 2017;8:637.

4. Bachero-Mena B, Pareja-Blanco F, Rodríguez-Rosell D, YáñezGarcía JM, Mora-Custodio R, González-Badillo JJ. Relationships between sprint, jumping and strength abilities, and $800 \mathrm{~m}$ performance in male athletes of national and international levels. J Hum Kinet. 2017;58:187-95.

5. Berthelot G, Sedeaud A, Marck A, Antero-Jacquemin J, Schipman J, Saulière G, Marc A, Desgorces FD, Toussaint JF. Has athletic performance reached its peak? Sports Med. 2015;45(9):1263-71.

6. Brown E. Running strategy of female middle distance runners attempting the $800 \mathrm{~m}$ and $1500 \mathrm{~m}$ "Double" at a major championship: a performance analysis and qualitative investigation. Int $\mathbf{J}$ Perform Anal Sport. 2005;5:73-88.

7. Burgess D, Naughton G, Hopkins W. Draft-camp predictors of subsequent career success in the Australian Football League. J Sci Med Sport. 2012;15(6):561-7.

8. Coast JR, Blevins JS, Wilson BA. Do gender differences in running performance disappear with distance? Can J Appl Physiol. 2004;29(2):139-45.

9. Coelho E Silva MJ, Figueiredo AJ, Moreira Carvalho H, Malina RM. Functional capacities and sport-specific skills of 14-to 15-year-old male basketball players: Size and maturity effects. Euro J Sport Sci. 2008;8(5):277-85.

10 Cohen J. Statistical power analysis for the behavioral sciences. Academic Press; 2013.

11. De Leeuw A-W, Meerhoff LA, Knobbe A. Effects of pacing properties on performance in long-distance running. Big Data. 2018;6(4):248-61. 
12. Deason J, Powers S, Lawler J, Ayers D, Stuart M. Physiological correlates to 800 meter running performance. J Sports Med Phys Fit. 1991;31(4):499-504.

13. Duffield R, Dawson B, Goodman C. Energy system contribution to 400-metre and 800-metre track running. J Sports Sci. 2005;23(3):299-307.

14. Duffield R, Dawson B, Goodman C. Energy system contribution to 1500-and 3000-metre track running. J Sports Sci. 2005;23(10):993-1002.

15. Folland JP, Allen SJ, Black MI, Handsaker JC, Forrester SE. Running technique is an important component of running economy and performance. Med Sci Sports Exerc. 2017;49(7):1412.

16. Hanley B. Pacing profiles and pack running at the IAAF World Half Marathon Championships. J Sports Sci. 2015;33(11):1189-95.

17. IAAF. About the IAAF. 2019. www.iaaf.org. Accessed 15 Apr 2019.

18. Ingham S, Whyte G, Pedlar C, Bailey D, Dunman N, Nevill A. Determinants of 800-m and 1500-m running performance using allometric models. Med Sci Sports Exerc. 2008;40(2):345-50.

19. Kyröläinen H, Belli A, Komi PV. Biomechanical factors affecting running economy. Med Sci Sports Exerc. 2001;33(8):1330-7.

20. Loturco I, Kobal R, Kitamura K, Fernandes V, Moura N, Siqueira F, Abad CCC, Pereira LA. Predictive factors of elite sprint performance: influences of muscle mechanical properties and functional parameters. J Strength Cond Res. 2019;33(4):974-86.

21. Nevill AM, Whyte G. Are there limits to running world records? Med Sci Sports Exerc. 2005;37(10):1785-8.

22. Piggott BG, McGuigan MR, Newton MJ. Relationship between physical capacity and match performance in semiprofessional Australian rules football. J Strength Cond Res. 2015;29(2):478-82.

23. Robertson S, Woods C, Gastin P. Predicting higher selection in elite junior Australian Rules football: the influence of physical performance and anthropometric attributes. J Sci Med Sport. 2015;18(5):601-6.

24. Sandford GN, Pearson S, Allen SV, Malcata RM, Kilding AE, Ross A, Laursen PB. Tactical behaviors in men's 800-m Olympic and world-championship medalists: a changing of the guard. Int J Sports Physiol Perform. 2018;13(2):246-9.
25. Sandford GN, Rogers SA, Sharma AP, Kilding AE, Ross A, Laursen PB. Implementing anaerobic speed reserve testing in the field: validation of $v V \mathrm{O}_{2 \max }$ prediction from $1500 \mathrm{~m}$ race performance in elite middle-distance runners. Int J Sports Physiol Perform. 2019;14(8):1-12.

26 Santos PA, Sousa CV, Barbosa LP, Aguiar SS, Sales MM, Simões HG, Nikolaidis PT, Knechtle B. Breaking the athletics world record in the 100 and 400 meters: an alternative method for assessment. J Sports Med Phys Fit. 2020;60(10):1317-21.

27. Seiler S, De JK, Foster C. The fall and rise of the gender difference in elite anaerobic performance 1952-2006. Med Sci Sports Exerc. 2007;39(3):534-40.

28. Sierer SP, Battaglini CL, Mihalik JP, Shields EW, Tomasini NT. The National Football League Combine: performance differences between drafted and nondrafted players entering the 2004 and 2005 drafts. J Strength Cond Res. 2008;22(1):6-12.

29. Spencer MR, Gastin PB. Energy system contribution during 200to $1500-\mathrm{m}$ running in highly trained athletes. Med Sci Sports Exerc. 2001;33(1):157-62.

30. Stojanović E, Ristić V, McMaster DT, Milanović Z. Effect of plyometric training on vertical jump performance in female athletes: a systematic review and meta-analysis. Sports Med. 2017;47(5):975-86.

31. Thiel C, Foster C, Banzer W, De Koning J. Pacing in Olympic track races: competitive tactics versus best performance strategy. J Sports Sci. 2012;30(11):1107-15.

32. Till K, Cobley S, O'Hara J, Morley D, Chapman C, Cooke C. Retrospective analysis of anthropometric and fitness characteristics associated with long-term career progression in Rugby League. $\mathrm{J}$ Sci Med Sport. 2015;18(3):310-4.

33. Wilder J. Basimetric approach (law of initial value) to biological rhythms. Ann N Y Acad Sci. 1962;98:1211-20.

34. Yoshida T, Udo M, Iwai K, Chida M, Ichioka M, Nakadomo F, Yamaguchi T. Significance of the contribution of aerobic and anaerobic components to several distance running performances in female athletes. Eur J Appl Physiol. 1990;60(4):249-53.

35. Young DC. A brief history of the Olympic games. New Jersey: Wiley; 2008. 